\title{
Customização em massa e reconfiguração dinâmica de produtos incompletos
}

Alice Bodanzky é designer pela ESDI/ UERJ e cenógrafa pela UNI-RIO. Fez o mestrado em Media Technology na Leiden University (Holanda). Atualmente é doutoranda no laboratório NEXT da PUC-Rio, tendo como foco de sua pesquisa a materialização expressiva de dados. Ao longo da sua formação passou ainda por diversas instituições acadêmicas, tais como FHP (Potsdam), UDK (Berlim), Kabk (Den Haag) e TUDelft (Delft). Ocupa hoje o cargo de cenógrafa da UERJ. Trabalhou como designer em empresas como YDreams Brasil (Rio de Janeiro), Mediamatic (Amsterdam) e ART+COM (Berlim) e em centros de pesquisa, incluindo Hyperbody/TUDelft (Delft) e Visgraf/IMPA (Rio de Janeiro). Recebeu o prêmio Most Creative Design na Microsoft Research Faculty Summit 2005 pelo projeto Saudade e menção honrosa no Red Dot Design Award 2015 pelo projeto Mater.

<alicebodanzky@gmail.com> ORCID: 0000-0001-9936-0505
Resumo $O$ artigo trata do tema da customização em massa em relação a processos contemporâneos de produção e de consumo cada vez mais digitalizados. Discute abordagens e desafios do projeto de produtos dentro da lógica tradicional da customização. Apresenta os conceitos de "produto incompleto" e "reconfiguração dinâmica" como resposta a avanços recentes, em especial, a introdução de tecnologias de interação com usuários, a crescente relevância dos contextos de uso e os modelos de negócio baseados nas relações de serviço. Conclui com alguns desdobramentos promissores do ponto de vista da evolução de estratégias de customização de produtos físicos.

Palavras chave Customização em massa, Projeto de produto, Produtos incompletos.

\section{Mass customization and dynamic reconfiguration of incomplete products}

Abstract This paper presents, from the point of view of Information Design, a comparative analysis from the graphic representation of a research project through the mapping of information by Robert Horn (1993) and the graphic tools of Yvonne Hansen (1999). The objective of this paper is to compare the representation of a research project from the study of the tools proposed by these authors. The methodology adopted is based on bibliographical research as the main technical procedure and from this practice it is proposed to analyze comparatively the two tools. As results, it was noted that Horn's information mapping is not efficient in the initial phase of problem study but it is useful when it is necessary to organize information; and that Hansen's graphic tools can be used in the initial process of specifying a problem because they are efficient in clarifying ideas and understanding concepts.

Keywords Mass customization, Product design, Incomplete products. 
Jorge Roberto Lopes dos Santos possui Post Doc pela Deakin University - Australia; PhD - Royal College of Art

- Londres, Reino Unido; Mestrado em Engenharia pela COPPE UFRJ e Graduação em Desenho Industrial pela Escola de Belas Artes da UFRJ. É coordenador do NEXT - Núcleo de Experimentação Tridimensional do Departamento de Artes e Design da PUC Rio, Pesquisador da Pos Graduação em Design da PUC Rio, Pesquisador do Laboratorio de Modelos Tridimensionais do Instituto Nacional de Tecnologia - MCTIC e Pesquisador Colaborador do Museu Nacional - MN - UFRJ $<$ Jorge.lopes@puc-rio.br> ORCID: 0000-0001-9702-7573

Cláudia Mont'Alvão possui graduação em Desenho Industrial, Projeto de Produto, pelo Centro Universitário da Cidade (1994), Mestrado e Doutorado em Engenharia de Transportes pela Universidade Federal do Rio de Janeiro (1997 e 2001). Atualmente é Professora Associada e Coordenadora do Programa de Pós Graduação em Design do PPGDesign PUC-Rio. Desde 2002 atua como Coordenadora do Laboratório de Ergodesign e Usabilidade de Interfaces (LEUI/ PUC-RIo). Como atividades decorrentes da atuação no LEUI/PUC-Rio é coordenadora geral dos eventos ERGODESIGN \& USIHC (desde 2000) e editora-chefe da Revista Ergodesign \& HCI. Contribui ainda como consultora ad hoc de varias agências de fomento, tais como CNPq, FAPESP e FAPEMIG. Pesquisa o estudo e a aplicação da Ergonomia nas áreas de informação/advertências, interação humano-computador, ambiente construído e sistemas de transportes. Bolsista de Produtividade do CNPq nivel 2 <ergonomiapuc@gmail.com> ORCID: 0000-0002-2882-5114

\section{Introdução}

A produção mecanizada em massa de produtos altamente padronizados, que culminou nos séculos XIX e XX, já não é suficiente para atender aos anseios da sociedade contemporânea. A demanda por produtos customizados, e até mesmo personalizados, vem sendo largamente impulsionada pela mudança de paradigma trazida pela era digital.Em seu livro The Alphabet and The Algorithm, Carpo (2011) afirma que a principal ruptura causada pela revolução digital foi o surgimento do conceito de variabilidade em oposição ao conceito de cópia idêntica. Segundo o autor, tudo que é digital é por princípio variável. E é justamente a inserção da variabilidade nos processos de concepção, produção e distribuição que vem permitido a oferta de produtos cada vez mais adequados às necessidades e às preferências individuais dos usuários.

Dessa maneira, a customização dos processos dos produtos de acordo com a demanda dos sob medida, mas também produtos reconfiguráveis de acordo com produtivos baseia-se na diferenciação programada usuários. Essa demanda pode ser trabalhada em suas diversas dimensões, de forma a oferecer aos usuários não somente produtos determinado contexto de uso. Embora exemplos sejam mais facilmente encontrados nos resultados de processos produtivos essencialmente digitais e no setor de serviços, algumas estratégias emergentes da economia digital vem sendo aliadas a avanços tecnológicos recentes a fim de viabilizar a extensão de possibilidades de customização aos produtos físicos. Novas tecnologias, tais como manufatura digital, materiais inteligentes e internet das coisas, juntamente com novos modelos de negócios, especialmente estratégias fundamentadas em relações de serviço, têm permitido a reprogramação de produtos durante a experiência de uso do consumidor. Assim, pode-se dizer que esses produtos tornam-se permanentemente "incompletos", pois são abertos a customização no do âmbito do consumo. Essas mudanças causam um profundo impacto na geração de valor, tanto ponto de vista do usuário quanto da empresa e, por isso, apontam avanços promissores para a customização em massa. Apesar do seu potencial evidente para o campo, o tema ainda é pouco explorado pelo design. Este artigo visa, portanto, apresentar um referencial teórico que ajude a avançar na discussão tanto teórica quanto prática do mesmo. Para tal foram selecionados alguns projetos, desenvolvidos em laboratórios de ponta, assim como autores cujas publicações mais recentes contribuem para delinear as abordagens e os desafios expostos a seguir.

$\mathrm{Na}$ próxima seção serão definidos e exemplificados o conceito de customização em massa e alguns desafios e abordagens comuns ao projeto e à comercialização de produtos desse tipo. Na seção 3, a estratégia tradicional da customização em massa é problematizada tendo como pano de fundo o novo paradigma na área do marketing do Service-Dominant Logic. Mais especificamente,serão apresentados os conceitos de "produto incompleto" e "reconfiguração dinâmica" como decorrentes de rearranjos produtivos que proporcionam um papel mais relevante dos contextos de uso e uma 
Manuela Quaresma possui graduação em Desenho Industrial pela UniverCidade (1996), mestrado (2001) e doutorado (2010) em Design pela Pontifícia Universidade Católica do Rio de Janeiro (PUC-Rio). Já trabalhou e pesquisou para empresas estrangeiras como Ford Motor Company e Institut Français de Sciences et Technologies des Transports (IFSTTAR) e, atualmente, é pesquisadora e professora do departamento de Artes \& Design da PUC-Rio. Manuela leciona tanto no curso de graduação quanto no de pós-graduação em Design (especialização, mestrado e doutorado), com foco no Design Centrado no Usuário. Seus interesses em pesquisa (no LEUI | Laboratório de Ergodesign e Usabilidade de Interfaces) incluem tópicos relacionados a ergodesign, design centrado no humano, experiência do usuário (UX), interação humano-computador e humano-produto, usabilidade, design de interação, design de aplicativos, ergonomia e design automotivo, veículos autônomos, sistemas de informação e de assistência ao motorista.

<mquaresma@puc-rio.br>

ORCID: 0000-0001-5683-7692 participação mais ativa dos usuários na co-criação de valor em produtos customizáveis. $O$ artigo conclui com breves apontamentos de caminhos a serem seguidos em projetos de customização que façam uso expressivo da nova estratégia apresentada.

\section{Customização em massa: abordagens e desafios de projeto serviços) produtos}

A customização em massa consiste no método de desenvolver e oferecer bens (e/ou serviços) customizados/personalizados a consumidores ou usuários a preços equivalentes aos de produtos produzidos emmassa. Em outras palavras, é uma abordagem de concepção, desenvolvimento e comercialização de produtos que minimiza a distância entre o produto ideal, aquele que preenche as necessidades e preferências individuais dos consumidores, sejam elas emocionais, funcionais, ergonômicas etc., e o produto disponível, o qual se beneficia da redução de custos proporcionado pela produção em larga escala (FERGUSON; OLEWNIK; CORMIER, 2014). Essa definição alinha-se às proposições de Piller (2004), que identifica nas abordagens de customização três dimensões, quais sejam:

- Estilo: refere-se a modificações no produto em termos de forma, cor, textura, entre outros aspectos referentes aos sentidos do consumidor, principalmente o visual;

- Adequação e conforto (antropometria): baseia-se na adequação das dimensões físicas do produto como, por exemplo, ajustes de roupa à medida do corpo de cada usuário;

- Funcionalidade: remete às mudanças nos atributos do produto de ordem técnica, tais como voltagem e interface.

Piller (2004) propõe ainda a hipótese de que a customização em massa de produtos será mais bem sucedida quando essas três dimensões foram aplicadas simultaneamente. Entretanto, empresas comumente abordam apenas um desses pontos de cada vez, muitas vezes devido à dificuldade em se realizar com sucesso inovações em qualquer uma das dimensões. Tais desafios são resumidos por Zipkin (1997) em função de três questões principais:

1. Dificuldade na elucidação das necessidades e preferências individuais dos consumidores que levem a uma customização significativa;

2. Explanação de métodos e mecanismos de configuração que dêem suporte à customização sem sobrecarregar o consumidor com opções demais;

3. Criação de métodos de produção flexíveis o suficiente para que a customização se realize. 
Das dimensões mencionadas anteriormente, adequação e conforto talvez seja aquela cuja aplicação possa ser resolvida mais facilmente, pois se trata de adequar as medidas de um produto a outro corpo de forma objetiva e mensurável. Nesse caso, os desafios levantados por Zipkin tornam-se menos complexos, uma vez que as necessidades dos usuários podem ser claramente mapeadas e, muitas vezes, igualam-se às suas preferências, ou seja, à adequação física do produto. Por se tratarem de algo mensurável por meio da antropometria, as necessidades dos usuários se tornam também parametrizáveis, o que permite a customização programada do produto e, por conseguinte, evita a oferta de opções demais para o usuário final. Em outras palavras, bastaria coletar e inserir as medidas de determindo usuário em algum sistema de suporte para que a forma do produto fosse automaticamente ajustada para ele. Esse tipo de customização é especialmente interessante para determinados setores, por exemplo, a indústria esportiva. A adequação de roupas, acessórios e equipamentos às medidas corporais de atletas e usuários em geral permite não apenas uma melhor performance, como também normalmente aumenta a segurança proporcionada por esses produtos.

Um estudo conduzido por Ellena et al. (2016) trata justamente desta questão ao analisar a dimensão interna de capacetes de bicicleta para proporcionar maior segurança. Baseando-se em antropometria 3D, técnicas de engenharia reversa e análise computacional, os autores desenvolvem um método inovador para investigar e comparar o quão precisa é a adequação desses produtos a cabeças dos usuários e propõem um índice de adequação de capacetes. De acordo com o método, primeiramente, a cabeça dos participantes é escaneada por um escaner 3D de alta resolução. Os dados coletados são processados e as imperfeições, corrigidas. Em seguida, valendo-se de uma técnica de engenharia reversa, os três modelos comerciais de capacete de bicicleta escolhidos para o estudo são também escaneados e seus dados processados. Utilizando como referência um terceiro escaneamento do participante vestindo o capacete, o modelo 3D virtual inicial da cabeça é alinhado ao modelo virtual 3D do capacete (FIG. 1).
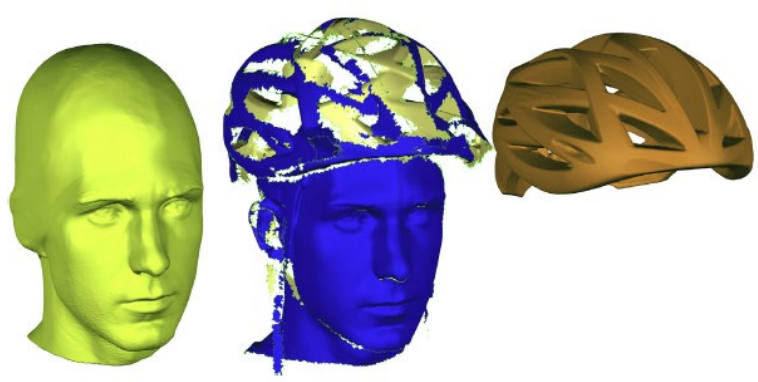

Fig 1. Alinhamento dos modelos virtuais escaneados. Fonte: ELLENA ET AL. 2016, p 198.
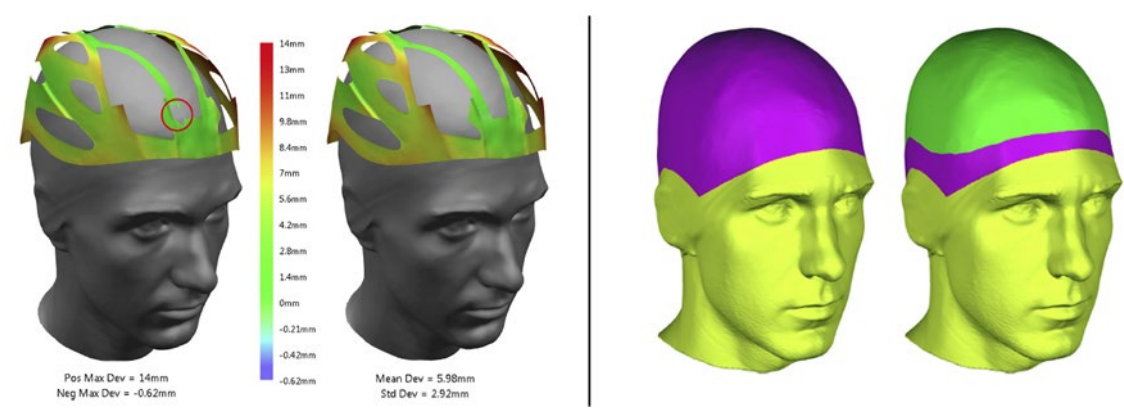

Fig 2. Resultado gráfico da análise do SOD e GU à esquerda e do HPP à direita.

Fonte: ELLENA ET AL. 2016, p 199, 200. 
A partir do modelo final é possível analisar precisamente o intervalo entre a área interna do capacete e a superfície da cabeça do participante, medida determinante para a segurança do usuário em caso de acidente. Essa análise baseia-se em 3 parâmetros (FIG. 2): (1) Standoff Distances (SOD), que é a distância entre a cabeça do usuário e o forro do capacete; (2) Gap Uniformity (GU), que consiste no desvio padrão da distribuição do intervalo existente; e (3) Head Protection Proportion (HPP), que é definido pela proporção da cabeça do usuário protegida pela área do capacete. Esses parâmetros compõem a fórmula que define o índice de adequação do capacete. Segundo os autores, o índice ajuda a compreender detalhadamente a eficiência de capacetes de bicicleta na proteção de usuários e pode ainda informar as fases de design e desenvolvimento de produtos customizados.

Essa pesquisa evidencia que mesmo quando a identificação da necessidade do usuário (nesse caso, a adequação do produto a medidas corporais) não representa uma questão a ser desvendada, ainda assim o processo de captura da informação necessária para que haja uma customização significativa não é uma tarefa trivial para a empresa.

o desafio, contudo, torna-se ainda maior quando as outras dimensões de customização enumeradas por Piller (2004) - estilo e funcionalidade - entram em jogo. O projeto Cell cycle, desenvolvido pelo estúdio de design Nervous System, ilustra bem esse cenário. Com o objetivo de oferecer aos clientes uma joia customizável tanto do ponto de vista estético quanto ergonômico e funcional, a empresa desenvolveu um sistema que permite ao usuário configurar um anel da maneira que ele desejar. $O$ cliente pode controlar em uma interface online, entre outros parâmetros, tamanho e espessura da joia, sua intensidade, forma e estilo do padrão estrutural, bem como os materiais. (FIG. 3)

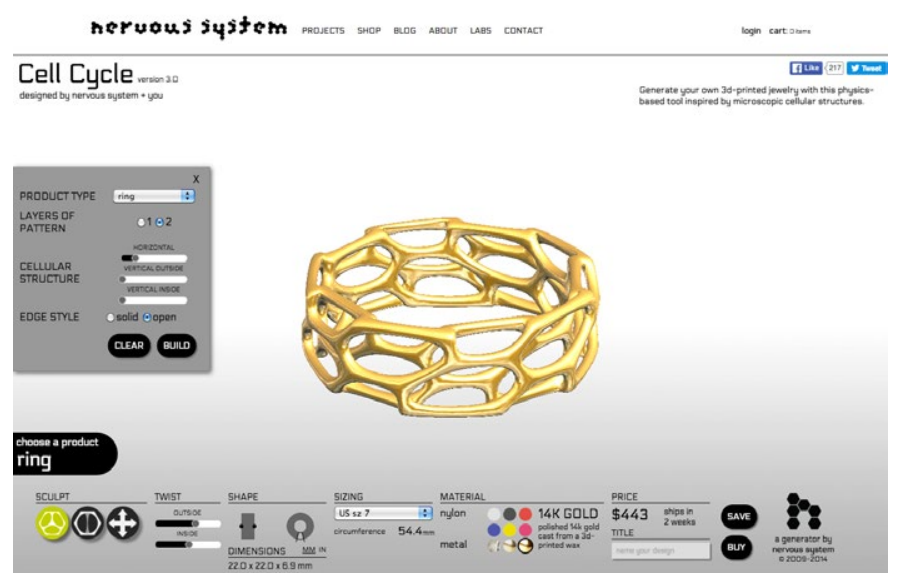

Fig 3. Interface que permite ao usuário customizar a forma da joia.

Fonte: www.n-e-r-v-o-u-s.com/cellcycle/?t=0

Uma vez escohida a forma final, a joia é produzida por uma impressora 3D e entregue ao cliente. Embora o projeto resolva as questões principais relativas à customização levantadas por Zipkin (1997), mencionadas acima, a ressalva feita pelo autor sobre o excesso de opções oferecidas ao 
consumidor se confirma nesse caso, pois a quantidade de controles disponíveis na interface se mostra excessiva para o usuário comum. Sobrecarregado com tantas opções, ele pode acabar perdendo o interesse ou ficando indeciso, não efetivando a compra da joia no fim.

Uma outra questão relevante de ser observada sobre o assunto da customização é o método de produção utilizado. A impressão 3D permite a fabricação de objetos únicos a preços similares a itens idênticos, o que em princípio torna essa tecnologia ideal para viabilizar projetos de customização em massa. No entanto, atualmente o longo tempo característico da impressão 3D ainda não permite uma produção em larga escala. Essa constatação leva a autores como Anderson (2012) a afirmar que o que os novos modelos de fabricação digital realmente possibilitam é a produção seriada para mercados de nicho.

Outro ponto crítico definido pela capacidade produtiva da tecnologia atual é a necessidade de se trabalhar com um espaço finito de soluções. Diferentemente do artesanato tradicional, que possibilita a customização quase ilimitada de produtos, os sistemas atuais, por mais flexíveis que sejam, operam sobre o princípio da modularidade e, por isso, predefinem os módulos a serem utilizados, o que acaba por limitar o universo de soluções possíveis.

Por fim, um último aspecto que contribui para a viabilidade da customização em massa é o fato de o produto só ser fabricado após a conclusão do pedido do consumidor. Isto é, a flexibilização da cadeia de produção e fornecimento permite que a especificação do produto seja adiada ao máximo, ocorrendo apenas no momento de troca/transação com o consumidor.

A conjunção dos fatores discutidos acima é decisiva para que a customização em massa seja, de fato, viável em vistas da tecnologia e dos métodos projetuais de hoje. O que se tem como resultado, sem dúvida, são produtos fabricados sob medida para cada usuário. Embora isso represente um avanço considerável na maneira como se consome atualmente, a pesquisa em customização em massa já vem apontando um novo caminho por onde o conceito pode evoluir: a customização de produtos no contexto de uso e sob demanda.

\section{Novas estratégias de customização}

\section{Tailoring e a Goods-Dominant Logic (GDL)}

O conceito de variabilidade introduzido pela revolução digital se apresenta de diversos modos no contexto da customização de produtos físicos. De maneira mais direta, ajudou a formar a escola atual de customização em massa classificada de tailoring (NG et al., 2015). Como foi exposto na seção anterior, essa estratégia se vale de avanços tecnológicos, de métodos de produção e manufatura ágeis e flexíveis e de novos modelos de negócio para oferecer produtos sob medida para cada cliente, sem abrir mão dos benefícios da economia de larga escala. Do ponto de vista de avan- 
ços recentes na teoria do marketing, tal estratégia enquadra-se na chamada Goods-Dominant Logic (GDL), cujo foco está nas transações de bens materiais estabelecidas entre dois atores econômicos principais: provedores e consumidores (VARGO; LUSCH, 2004).

De acordo com a perspectiva GDL, a definição do valor de determinado produto customizado ocorre no âmbito de sua produção, portanto, antes dele ser transferido e usado pelo consumidor. Assim, a proposição de valor do produto é tida como de responsabilidade da empresa, como também o é a de assegurar a satisfação do consumidor em receber exatamente o que havia pedido. Portanto, um dos objetivos buscados é adiar essa transação do produto o máximo possível dentro da cadeia de produção e fornecimento, pois quanto mais tarde for o momento de especificação final por parte do usuário, mais customizado o produto será (YANG; BURNS, 2003). Em decorrência disso todas as fases de desenvolvimento e distribuição do produto, tais como design, fabricação, montagem etc., passam a ser baseadas no pedido do consumidor. Para tal, a cadeia produtiva e de fornecimento se apoia fortemente na modularidade e flexibilidade dos sistemas empregados. Vale ressaltar, entretanto, que de acordo com essa abordagem a experiência de uso encontra-se fora da cadeia de valor. Ou seja, a participação do usuário na produção de valor em produtos customizados restrinje-se à entrada de certas informações sobre suas necessidades pessoais ou à seleção de determinados atributos a serem personalizados no produto. Como mencionado acima, é dessa maneira que a produção de uma extensa variedade de produtos customizados pode ser garantida, minimizando a distância entre o produto ideal (personalizado) e o produto possível (viável).

\section{Platform e a Service-Dominant Logic (SDL)}

A economia digital, contudo, vem expandindo o significado de variabilidade para além do conceito de produtos variados (não idênticos). A fluidez da computação tem penetrado os mais diversos meios, de produção e de uso, através do software. A computação pervasiva agora permite que produtos sejam não apenas individualizados para cada usuário, mas também reprogramados radicalmente em termos de estética, função e adequação de acordo com o contexto de uso. Nesse cenário, a definição do conceito de customização em massa aproxima-se da visão de Davis (1987) de oferecer aos consumidores "exatamente o que eles querem quando eles querem". Nos produtos essencialmente digitais essa proposição é, sem dúvida, o caminho natural graças à intrínseca maleabilidade do software. No entanto, no universo de produtos físicos esse grau de customização exige novas estratégias aliadas a avanços tecnológicos consideráveis para se tornar realidade.

Um das novas estratégias, denominada de platform, propõe que a customização aconteça no próprio âmbito do consumo, isto é, depois do produto já ter sido transferido para o usuário. Ela se apoia na teoria ServiceDominant Logic (SDL), que reserva ao consumidor um papel muito mais ativo nas relações econômicas ao sugerir que bens e serviços são sempre resul- 
tados da co-criação entre empresa e usuário e que todo valor é determinado pelo último durante a experiência de uso (VARGO; LUSCH, 2004). Em relação à customização em massa, a SDL considera usuários um elemento essencial do sistema produtivo, que contribui definitivamente com a produção de valor a partir de informações pessoais e experiências relativos ao uso de produtos em determinado contexto. 0 provedor, por sua vez, passa a ter responsabilidade também sobre o momento da experiência do usuário, obrigatoriamente incluindo-o na cadeia de gestão. Assim sendo, a fronteira de transação entre provedor e o consumidor alinha-se ao momento de utilização dos produtos customizados (NG et al., 2015).

\section{Produtos incompletos e Reconfiguração dinâmica}

Para se adequar a esse novo paradigma é necessário que o produto customizado seja projetado apenas "parcialmente", deixando ao consumidor a tarefa de completar a oferta de valor durante a experiência de uso. Em consonância com esse pensamento, Davies e Ng (2015) introduzem o termo produto incompleto para se referir a esse produto que, por meio de uma arquitetura modular, é capaz de se reconfigurar dinamicamente de acordo com o contexto de uso e sob demanda. Desse modo, o produto pode ter algumas funcionalidades adicionadas, ou melhor, reprogramadas mesmo depois de ter sido transferido para o usuário. Tais produtos passam a exibir características dominantes de serviço - daí, o enquadramento no paradigma SDL - pois estão aptos a prover novos serviços ao consumidor em uma conjuntura de transformações constantes. $O$ usuário, por sua vez, converte-se em peça fundamental desse sistema, pois não somente assume o papel de "completar o produto" a cada experiência, como também atua como um filtro redutor da complexidade do contexto, deixando passar apenas a informação que interessa. Nessa dinâmica, a realização da proposta de valor adia-se indefinidamente, uma vez que o produto será especificado, customizado pelo usuário a cada nova experiência de uso, o que ocorre num modo contínuo e previamente indeterminado. Devido ao aspecto aberto e flexível das fronteiras de transação entre empresa e usuário, pode-se constatar que o produto incompleto apresenta uma alta tolerância para a variedade. Além, disso, ele sintetiza um processo produtivo não-linear, onde cada parte do sistema contribui com seus próprios recursos para encontrar a adequação ótima entre os atores, a oferta e o contexto de uso.

O smartphone (FIG. 4) é um ótimo exemplo de aplicação da estratégia de platform. Ele é um produto que se beneficia da economia de larga escala para a produção do seu hardware, ao mesmo tempo em que permite que a customização aconteça por meio do software. Pode ser categorizado, portanto, como um produto incompleto, que, graças a seus aplicativos, possibilita a personalização durante a experiência de uso de acordo com demanda. Dessa maneira, o smartphone vem redesenhando as fronteiras de transação, aproximando-as do espaço de consumo e permitindo o adiamento indefinido da criação de valor em produtos customizados. $O$ conceito de 
variabilidade torna-se tangível nesse caso, principalmente por causa do software, por permitir que o produto se comporte ora como uma plataforma de comunicação, ora como uma de jogo, e assim sucessivamente. Os limites de suas funções, portanto, não são previamente fixados; muito pelo contrário, não poderiam nem ser completamente imaginados a priori. Pode-se dizer que o produto exibe uma hiper-variabilidade (hyper-variety) de uso, exigindo cada vez mais engajamento do consumidor e abrindo infinitas possibilidades de customização.

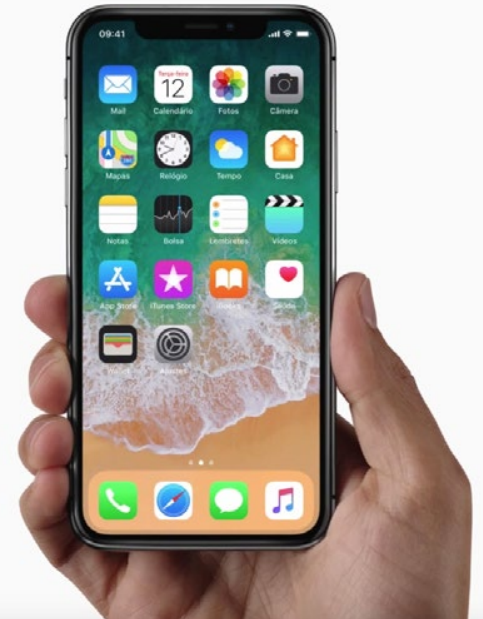

Fig 4. Hardware padronizado e software customizado através de aplicativos de um smartphone. Fonte: www.apple.com/br/iphone-x/

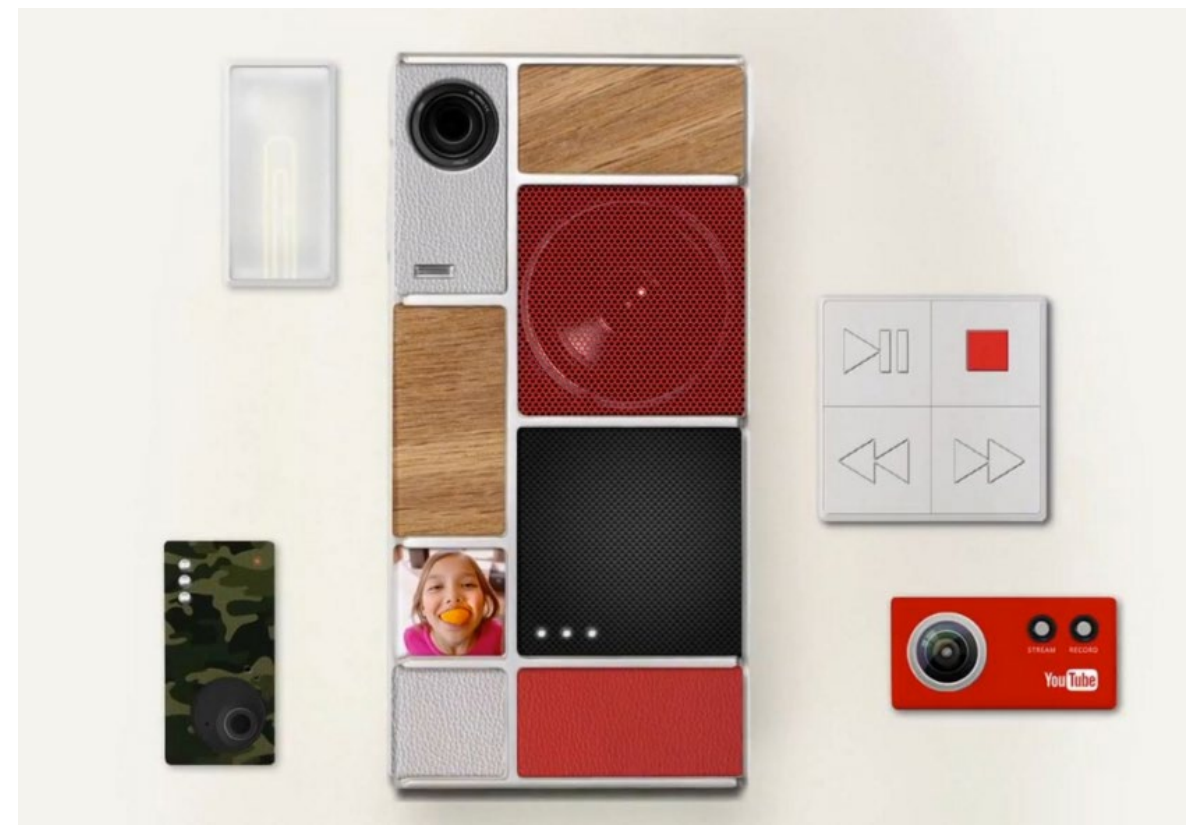

Fig 5. Resultado gráfico da anális do SOD e GU à esquerda e do HPP à direita. Fonte: ELLENA ET AL. 2016, p 199, 200.

Um último aspecto interessante de ser observado é que os aplicativos de um smartphone não precisam ser necessariamente providos pela empresa que concebeu, fabricou e comercializou o produto. Ou seja, a responsabilidade pela entrega da demanda de valor do consumidor e pelo cumprimento de suas expectativas pode ser compartilhada por um ou mais co-criadores do serviço.

Embora o smartphone já seja um exemplo clássico de sucesso no emprego da estratégia de platform em produtos físicos, nesse caso a customização propriamente dita não depende necessariamente da fisicalidade do produto, ou seja, do hardware. O projeto Ara (FIG. 5), desenvolvido pela empresa Google, explora justamente essa questão ao propor um novo mo- 
delo de smartphone cujo hardware é composto por módulos que podem ser adquiridos pelo usuário de acordo com as suas preferências. Por exemplo, o display, a câmera, o microfone ou a bateria extra são módulos isolados, e compatíveis, que podem ser acoplados a uma espécie de esqueleto do telefone para completar o produto de maneira personalizada. Esses componentes podem ser substituídos indefinidamente de acordo com as necessidades e as preferências do usuário. Isso significa que o hardware do produto pode ser customizado de acordo com a demanda e com o contexto de uso. A modularidade do sistema de customização, portanto, não se restringe ao software neste caso, que aliás assim como o smartphone comum é também customizável por meio de aplicativos.

Por um lado, pode-se afirmar que o projeto Ara, de fato, aborda a dimensão física do produto à luz das principais questões que definem a estratégia de platform: customização no consumo, adiamento indefinido, produto incompleto, reconfiguração dinâmica e realinhamento das fronteiras de transação. Por outro lado, é perceptível o estado finito do espaço de soluções que compõe os módulos do hardware. Devido a isso, torna-se evidente que o usuário customiza o produto a partir de uma variedade limitada e predefinida de soluções. Sob este ângulo, pode-se indagar se o projeto se aproximaria mais da estratégia de tailoring. De todo modo, fica claro o tamanho do desafio que é pôr em prática no mundo físico essa nova estratégia. Basta dizer que o projeto foi interrompido pela Google em 2016.

Outra obstáculo a ser superado pela empresa está relacionada à informação gerada sobre o contexto de uso e se resume a três desafios enumerados abaixo (NG et al., 2015):

1. Informação assimétrica: informações sobre o contexto de uso podem não ser visíveis para a empresa após a venda do produto;

2. Complexidade de informação: mesmo em condições simétricas em que a informação esteja disponível, a empresa pode ter dificuldade em organizá-la de maneira a viabilizar a customização;

3. Informação incompleta: informações sobre o uso de determinado produto ou sobre seu contexto futuro de uso podem não ser completas a ponto de se tornarem úteis para a empresa.

Os próprios autores acima indicam um possível caminho para solucionar esse problema: internet das coisas. Esse conceito pressupõe que em um futuro próximo todos os objetos físicos terão componentes eletrônicos imbutídos, o que disponibilizará toda a potencialidade do universo digital em qualquer ponto do nosso ambiente. Dessa forma, a computação torna-se realmente ubíqua, não dependendo mais de aparelhos especializados para ser acessada, tais como computadores ou smartphones. Isso significa que bilhões de objetos estarão interconectados e serão capazes de sentir e proces- 
sar informações e ainda de atuar diretamente e de forma contextualizada.

A visão proposta pela internet das coisas resolveria os pontos mencionados acima. A utilização de sensores aliada à conectividade, por exemplo, permitiria observar de perto a experiência de uso de produtos, tornando visíveis as atividades e o engajamento dos consumidores. Por conseguinte, obtém-se uma noção mais completa e verdadeira das preferências dos usuários, o que possibilitaria ofertas adequadas para cada demanda. A presença de processadores por toda parte, por sua vez, eliminaria o problema da complexidade de informação, pois permitiria que ela fosse gerada, coletada, analisada e processada in loco, imediatamente e de forma distribuída em rede, atenuando assim o volume de dados a ser trabalhados ao mesmo tempo. A "informação incompleta" apontada deixaria de ser uma questão, uma vez que o provedor não precisaria mais antever o uso futuro para projetar a oferta de valor. Pelo contrário, a capacidade de observação e ação imediata proporcionada pela tecnologia enfoca essa oferta sempre em seu tempo presente, que está em constante transformação. 0 objetivo passa a ser, de fato, projetar o produto de maneira que ele seja capaz de se reconfigurar dinamicamente para responder e atender prontamente a demanda. De certa maneira, isso indica que é necessário dotar cada objeto de inteligência própria, mesmo que ela seja artificial, pois a pré-programação do espaço de soluções já não parece ser suficiente nesse cenário.

Alguns projetos nesse sentido vêm sendo desenvolvidos em laboratórios de pesquisa. É o caso do Topobo (RAFFLE; PARKES; ISHII, 2004), um brinquedo 3D composto por peças modulares capazes de aprender e reproduzir movimentos físicos (FIG. 6). O usuário monta as pecinhas e as movimenta no espaço, e os módulos são capazes de memorizar o movimento e repetí-lo até que um novo gesto seja ensinado.

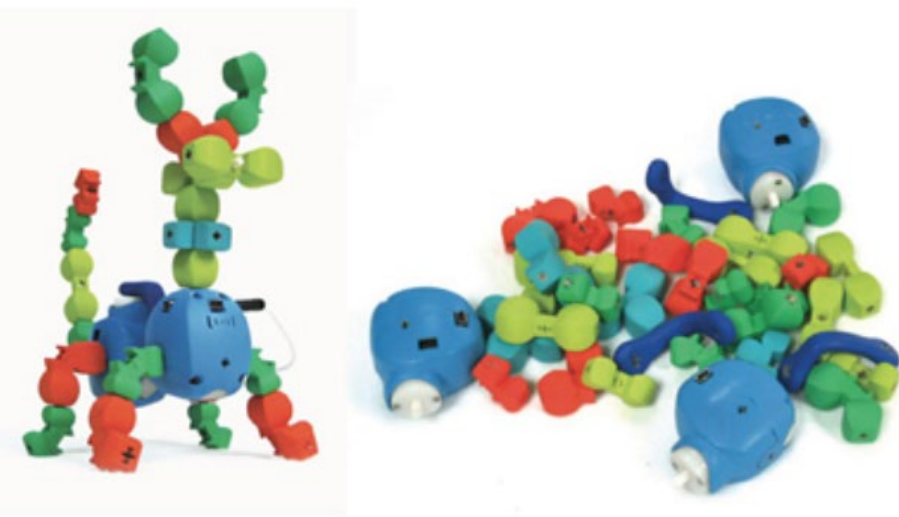

Fig 6. Projeto desenvolvido no MIT Media Lab, Topobo memoriza as interações dos usuários e as reproduz. Fonte: RAFFLE; PARKES; ISHII, 2004

Embora em sua versão atual os componentes do Topobo ainda não estejam conectados à Internet, o projeto proporciona uma visão do que a capacidade de reconfiguração dinâmica pode representar na experiência 
de uso de objetos físicos inteligentes, isto é, capazes de se "auto- customizar" de acordo com o contexto de uso.

Experiências como essa indicam, portanto, um caminho promissor de como tecnologias, tais como internet das coisas, manufatura digital e materiais inteligentes, atreladas a novas estratégias e à lógica dominante de serviços vão moldar produtos verdadeiramente incompletos. Por fim, permitindo que o provedor se beneficie da economia de escala ao mesmo tempo em que os usuários obtenham "o que eles querem quando eles querem".

\section{Conclusão}

Este artigo apresentou o conceito de variabilidade introduzido pela era digital e demonstrou como ele se manifesta na customização de produtos físicos. Como descrito e exemplificado acima, a maneira em que a personalização de produtos ocorre depende consideravelmente das estratégias e das tecnologias aplicadas. Se tailoring é empregado, o foco está na produção de produtos sob medida. A flexibilização e a modularidade dos meios de produção, aliadas à manufatura rápida, desempenham um papel fundamental na viabilização desse tipo de customização. A Goods-Dominant Logic norteia esse processo, no qual o ponto máximo do adiamento da especificação do produto por parte do consumidor coincide com o instante de sua transação com a empresa.

Do ponto de vista da abordagem mais recente de platform, o foco passa a estar na inclusão da experiência de uso como fator determinante do processo de customização. Neste caso, a Service-Dominant Logic opera como pano de fundo para orientar a produção de produtos incompletos, cuja customização se dá no próprio âmbito do consumo, a partir de informações advindas dos próprios usuários e do engajamento dos mesmos com os artefatos em questão. $O$ adiamento, neste caso, torna-se indefinido na medida em que as fronteiras da transação entre empresa e consumidor alinhamse ao contexto de uso e à demanda. A viabilização dessa nova abordagem depende fortemente de avanços tecnológicos em áreas emergentes, como internet das coisas e materiais inteligentes.

O referencial teórico apresentado neste artigo teve como objetivo avançar a discussão de um tema ainda pouco explorado na área do design, na esperança de que as visões expostas possam indicar caminhos para que a reconfiguração dinâmica de produtos físicos torne-se cada vez mais não apenas objeto de pesquisa, mas também tópico de investigações e aplicações práticas que venham a proporcionar inovações significativas para usuários e empresas. 


\section{Referências}

ANDERSON, C. Makers: The New Industrial Revolution. New York: Crown Business, 2012. CARPO, M. The Alphabet and the Algorithm. MIT Press, 2011.

DAVIES, P.; NG, I. Moving towards the Incomplete: A Research Agenda for the Development of Future Products in the Digital Economy. Procedia Manufacturing, 6th International Conference on Applied Human Factors and Ergonomics (AHFE 2015) and the Affiliated Conferences, AHFE 2015. v. 3, p. 3368-3374, 2015.

DAVIS, S. M. Future Perfect. Boston: Addisonc Wesley, 1987.

ELLENA, T. et al. The Helmet Fit Index: An intelligent tool for fit assessment and design customisation. Applied Ergonomics, v. 55, p. 194-207, 2016.

FERGUSON, S. M.; OLEWNIK, A. T.; CORMIER, P. A review of mass customization across marketing, engineering and distribution domains toward development of a process framework. Research in Engineering Design, v. 25, n. 1, p.11-30, 2014.

NG, I. et al. Contextual variety, Internet-of-Things and the choice of tailoring over platform: Mass customisation strategy in supply chain management. International Journal of Production Economics, v. 159, p. 76-87, 2015.

PILLER, F. T. Mass Customization: Reflections on the State of the Concept. International Journal of Flexible Manufacturing Systems, v. 16, n. 4, p. 313-334, 2004.

RAFFLE, H. S.; PARKES, A. J.; ISHII, H. Topobo: A Constructive Assembly System with Kinetic Memory. Proceedings of the SIGCHI Conference on Human Factors in Computing Systems. Anais...: CHI '04.New York, NY, USA: ACM, 2004Disponível em: <http://doi.acm. org/10.1145/985692.985774>. Acesso em: 1 set. 2016

VARGO, S. L.; LUSCH, R. F. Evolving to a New Dominant Logic for Marketing. Journal of Marketing, v. 68, n. 1, p. 1-17, jan. 2004.

YANG, B.; BURNS, N. Implications of postponement for the supply chain. International Journal of Production Research, v. 41, n. 9, 2003.

ZIPKIN, P. The Limits of Mass Customization. MIT Sloan Management Review, v. 42, n. 3, p.81-87, 1997. 